\title{
Resilience and the Role of Depressed and Anxious Mood in the Relationship Between Perceived Social Isolation and Perceived Sleep Quality During the COVID-19 Pandemic
}

\author{
Arwa Ben Salah ${ }^{1}\left[\right.$ Briana N. DeAngelis $^{2} \cdot$ Mustafa al'Absi $^{2}$
}

Accepted: 1 December 2020 / Published online: 7 January 2021

(c) International Society of Behavioral Medicine 2021

\begin{abstract}
Background The aim of the study was to examine the mediating role of depressed and anxious mood in the relationship between perceived social isolation and perceived sleep quality during the COVID-19 pandemic. We also aimed to investigate the moderating role of psychological resilience in this mediation.

Methods A cross-sectional study of adults (18+ years old) was conducted using an online, multi-language, international survey between March 31 and May 15, 2020. Simple and moderated mediation analyses were performed using the PROCESS macro for SPSS, with perceived social isolation as an independent variable, change in perceived sleep quality (during vs. before the COVID-19 pandemic) as a dependent variable, depressed and anxious mood (Patient Health Questionnaire-4, PHQ-4) as a mediator, and resilience (Brief Resilience Scale, BRS) as a moderator.

Results A convenience sample of 3816 participants ( 2692 = female) from 94 countries ( $47.4 \%$ USA) met criteria for inclusion in the analyses. Results showed that depressed and anxious mood mediated the relationship between perceived social isolation and change in perceived sleep quality. This mediation was moderated by resilience; the indirect effect of perceived social isolation on change in perceived sleep quality through depressed and anxious mood decreased as the level of resilience increased (index of moderated mediation $=0.008, \mathrm{SE}=0.003,95 \% \mathrm{CI}[0.001 ; 0.014]$ ).

Conclusions The study findings indicate benefits of psychological resilience in buffering negative effects of perceived isolation, suggesting potential benefits of developing targeted strategies to enhance resilience during times of significant crises.
\end{abstract}

Keywords Anxiety $\cdot$ Depression $\cdot$ Resilience $\cdot$ Sleep $\cdot$ Social isolation $\cdot$ COVID-19

\section{Introduction}

The world is facing a global health crisis unlike any since the 1918 influenza pandemic. Since its emergence in Asia late in 2019, coronavirus disease 2019 (COVID-19), caused by severe acute respiratory syndrome coronavirus 2 (SARSCoV-2), spread beyond countries' borders, and officially became a global pandemic [1]. The COVID-19 pandemic is one of the worst pandemics declared by the World Health

Mustafa al'Absi

malabsi@umn.edu

1 Community Medicine Department, Faculty of Medicine of Monastir, University of Monastir, Monastir, Tunisia

2 Family Medicine and Biobehavioral Health, University of Minnesota Medical School, Duluth, Minneapolis 55812, USA
Organization (WHO) as a Public Health Emergency of International Concern (PHEIC) [2]. As of July 12, 2020, 12,552,765 confirmed cases and 561,617 COVID-19 deaths worldwide have been reported by the WHO [3]. In addition to its economic and political impacts, the COVID-19 pandemic has affected individuals' physical, mental, and social wellbeing $[4,5]$.

In the absence of a vaccine to provide immunity against SARS-CoV-2, non-pharmaceutical interventions remain the pillars of infection prevention for COVID-19. For instance, to reduce the spread of SARS-CoV-2, many countries have implemented stay-at-home measures and reduced social interactions [6]. Feelings of social isolation and loneliness may increase in such circumstances, potentially adversely impacting physical and mental wellbeing. Indeed, a recent study conducted in Spain showed that levels of stress, anxiety, and depression were more pronounced after the issuance of a stayat-home order and during a confinement period [7]. These 
findings are consistent with previous evidence linking social isolation to depression and anxiety [8-10] and with previous studies showing increases in anxiety, depression, and stress levels among infected individuals, healthcare workers, and the general population during previous Severe Acute Respiratory Syndrome (SARS) outbreaks [11-14]. Recent observations indicate similar negative outcomes during the COVID-19 pandemic [7, 15]. For instance, Czeisler et al. [16] found that $40.9 \%$ of respondents in a USA sample reported adverse mental or behavioral health conditions and 30.9\% reported symptoms of anxiety and depressive disorders during the COVID19 pandemic. Other recent studies conducted in the USA have also shown an increase in the prevalence of depression during the pandemic compared to before the pandemic [17, 18]. These negative psychological states can have several consequences and can negatively affect sleep $[19,20]$.

Sleep disturbances are associated with altered immune functions [21-23], and enhancement of sleep quality during an infection may benefit the immune system and promote host defense [24, 25]. Therefore, it is important to understand risk factors and protective factors of sleep quality during infectious disease outbreaks, such as the COVID-19 pandemic.

Resilience, or "the ability to bounce back or recover from stress" [26], is one factor that may buffer the impact of pandemic-related isolation on negative moods and sleep. Specifically, individuals who are resilient may be less likely to experience negative outcomes that are associated with isolation and loneliness, including depression and anxiety symptoms as well as impaired sleep. In light of previous studies documenting relationships between social isolation, depression, anxiety, and sleep quality [8-10, 19, 27], we sought to extend previous findings by examining a moderated mediation model in which resilience moderates the relationship between perceived social isolation (subjective social isolation) and depressed/anxious mood as well as the relationship between perceived social isolation and sleep quality.

Based on research discussed earlier, we predicted a positive relationship between perceived social isolation and depressed/anxious mood and a negative relationship between depressed/anxious mood and perceived sleep quality. Furthermore, we predicted that resilience would attenuate perceived social isolation's relationships with depressed/anxious mood and perceived sleep quality.

\section{Methods}

\section{Study Design and Participants}

A cross-sectional descriptive study was conducted using an online survey built within the Qualtrics $\odot$ LLC survey software (co-headquarters in Provo, Utah, and Seattle, Washington). In addition to an English language version, 7 other translated versions of the survey (French, Spanish, Arabic, Italian, German, Russian, and Chinese) were available online. When available, existing translations of validated measures were used [28-40]; the consent form and remaining items were translated from English by native speakers of each language, and the content was verified by experts. Each translation was subsequently checked and verified by a second native speaker of the language. Links to the surveys were distributed from March 31 to May 15, 2020, via email circulation in professional and social groups (e.g., American Psychosomatic Society, Society for Research on Nicotine and Tobacco, National Institutes of Health, and University of Minnesota) as well as via Facebook/Instagram and other social media advertisements. The survey took approximately 15 min to complete, it was anonymous, and no incentive was provided to respondents. The survey landing page consisted of an electronic consent form, and this study was approved by the University of Minnesota Institutional Review Board. Participants were qualified for the study if they were 18 years of age or older, which was confirmed at the start of the survey with a question regarding age.

\section{Measures}

Demographics: Participants responded to questions regarding their age, sex at birth, level of schooling completed, marital status, employment status, country of residence, urban/ rural nature of their residence, and for residents of the USA, race/ethnicity.

Perceived Social Isolation: Participants reported to what extent they have felt socially isolated in the time since COVID-19 began spreading; they were asked "In the time since the coronavirus began spreading, to what extent have you felt socially isolated." The response scale ranged from 0 to $5(0=$ not at all; $1=$ slightly; $2=$ somewhat; $3=$ moderately; $4=$ quite a bit; $5=\mathrm{alot}$ ). This item was written for the purpose of the survey because it is face-valid.

Depressed and anxious mood: Participants also completed the 4-item Patient Health Questionnaire (PHQ-4) [41]. The instructions of the questionnaire were adjusted to ask about respondents' feelings related to depression and anxiety in the time since COVID-19 began spreading. PHQ-4 scores range from 0 to 12, and Cronbach's alpha was 0.87 .

Perceived sleep quality: Respondents were asked about their average sleep quality (perceived restfulness) both in the time since COVID-19 began spreading as well as before the virus began spreading. Specifically, participants were asked "In the time since the coronavirus began spreading, on average, how restful would you say your sleep has been?" and "Thinking back to before the coronavirus began spreading, on average, how restful would you 
say your sleep was?" Response scales ranged from 0 to 3 $(0=$ not at all; $1=$ somewhat; $2=$ moderately; $3=$ very much). These items were written for the purpose of the survey because they are face-valid.

Resilience: Resilience was measured using the Brief Resilience Scale [26], a 6-item measure designed to assess the ability to bounce back or recover from stress. Items were rated on a 5-point Likert scale that ranged from 1 to 5 and were averaged to create a total score, with higher scores indicating greater resilience. Cronbach's alpha for this measure was 0.85 .

\section{Data Management and Statistical Analysis}

Data were examined and verified according to standard scientific procedures. Only participants who responded to the two questions about sleep quality were included in this analysis. Prior to analysis, we created a variable to represent "change in perceived sleep quality," which consisted of the difference between perceived sleep quality since the spread of COVID-19 and perceived sleep quality before
COVID-19 (perceived sleep quality before COVID-19 was subtracted from perceived sleep quality since the spread of the virus). This variable served as our dependent variable; scores ranged from -3 to +3 . Negative change scores indicate decreases in perceived sleep quality, and positive change scores indicate increases in perceived sleep quality since the start of the spread of the virus.

Statistical analyses were performed using Statistical Package for the Social Sciences (SPSS) version 23.0. Descriptive data are presented as counts, percentages, means (m), and standard deviations (SD). Paired $t$ test was used to compare perceived sleep quality before and after the spread of COVID-19. Pearson's correlation coefficients $(r)$ were used to examine the observed correlations between our independent variable $(\mathrm{X}=$ Perceived social isolation), our proposed mediator $(\mathrm{M}=$ Depressed and anxious mood), our moderator ( $\mathrm{W}=$ Resilience $)$, and our dependent variable ( $\mathrm{Y}=$ Change in perceived sleep quality).

Simple mediation and moderated mediation models (Fig. 1) were tested using models 4 (simple mediation) and 8 (first stage and direct moderated mediation) of
Fig. 1 Simple mediation (a), first stage and direct moderated mediation (b) models. $X$ perceived social isolation, $M$ depressed and anxious mood, $W$ resilience, $Y$ change in perceived sleep quality
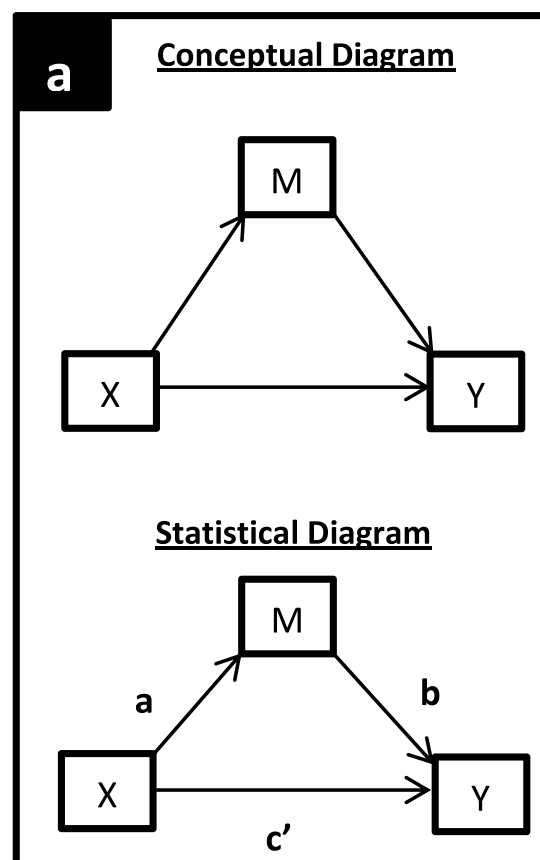

The indirect effect of $X$ on $Y$ through $\mathrm{M}=\mathrm{ab}$.

The direct effect of $X$ on $Y=c^{\prime}$.

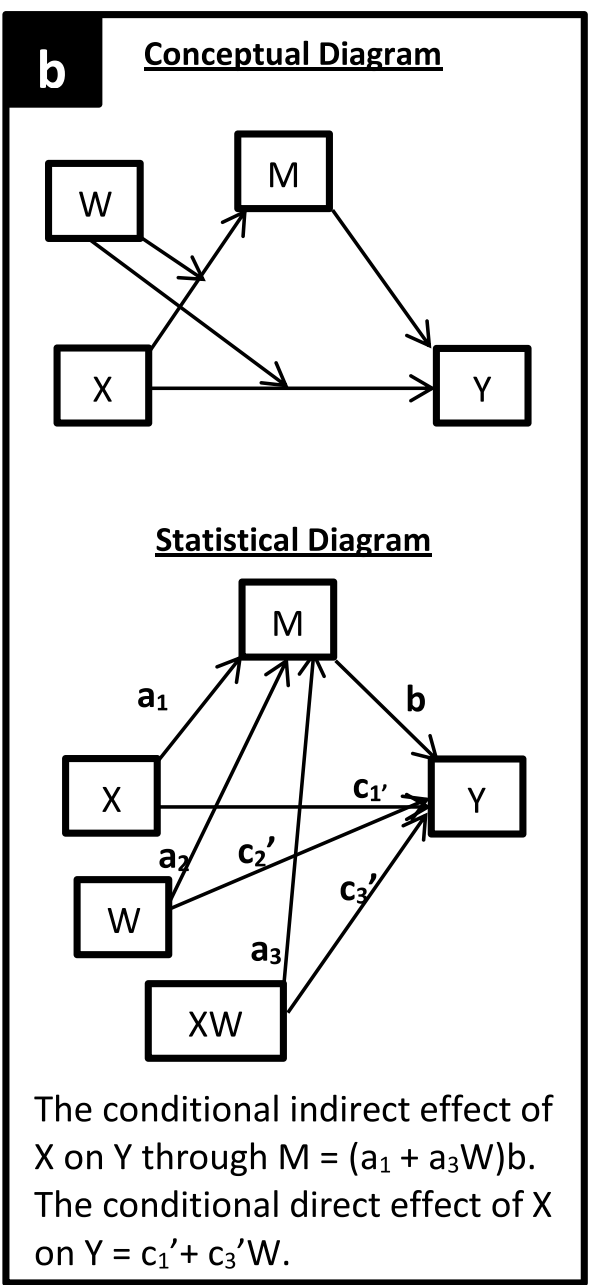


Hayes' PROCESS macro (version 3.5) [42], with 10,000 bias-corrected bootstrap samples. A $p=0.05$ was set as the critical level of significance. Indices of the indirect effect and of moderated mediation were considered statistically significant if the $95 \%$ confidence interval $(95 \%$ CI), estimated using bootstrap method, did not include zero. Significant moderation effects were probed at the mean and at one standard deviation above and below the mean of the moderator (resilience).

\section{Results}

\section{Sample Characteristics}

Respondents completed the survey between March 31 and May 15, 2020. The final sample of respondents included 3816 individuals. They were from 94 different countries and two-thirds of respondents lived in urban areas $(n=2502)$. Their mean age was $38.6(\mathrm{SD}=14)$ years. The main participant characteristics are summarized in Tables 1 and 2.

\section{Change in Perceived Sleep Quality and Its Correlations with Perceived Social Isolation, Depressed and Anxious Mood, and Resilience}

As seen in Table 2, sleep was perceived as less restful since the spread of COVID-19 $(t=-25.4, \mathrm{df}=3815$, $p<0.001)$. Compared with their perceived sleep quality before the pandemic, $40 \%(n=1527)$ of respondents reported perceiving lower sleep quality and $12 \%$ $(n=459)$ reported perceiving higher sleep quality during the pandemic. Pearson's correlations among the focal variables in the model are summarized in Table 3. Change in perceived sleep quality was negatively correlated with perceived social isolation $(r=-0.13$, $p<0.001)$ and with depressed and anxious mood $(r=-0.33, p<0.001)$. Change in perceived sleep quality was also positively correlated with resilience $(r=0.14, p<0.001)$.

\section{Simple and Moderated Mediation Analyses}

Figure 2 summarizes the results from the simple mediation model. As can be seen in Fig. 2, higher levels of perceived social isolation were associated with poorer perceived sleep quality during the pandemic compared to sleep quality before the pandemic, and this relationship was mediated by depressed and anxious mood.
Table 1 Main socio-demographic characteristics of the study participants

\begin{tabular}{|c|c|c|}
\hline & Number & Percent \\
\hline \multicolumn{3}{|l|}{$\operatorname{Sex}(n=3808)$} \\
\hline Male & 1101 & 28.9 \\
\hline Female & 2692 & 70.7 \\
\hline Other & 15 & 0.4 \\
\hline \multicolumn{3}{|l|}{ Country of residence $^{\mathrm{a}}(n=3803)$} \\
\hline USA & 1803 & 47.4 \\
\hline Germany & 277 & 7.3 \\
\hline India & 241 & 6.3 \\
\hline Tunisia & 201 & 5.3 \\
\hline \multicolumn{3}{|l|}{ Race (for USA residents) $(n=1789)$} \\
\hline White & 1687 & 94.3 \\
\hline Non-white & 102 & 5.7 \\
\hline \multicolumn{3}{|l|}{ Marital status $(n=3763)$} \\
\hline Never married & 1569 & 41.7 \\
\hline Married & 1874 & 49.8 \\
\hline Married but separated & 50 & 1.3 \\
\hline Divorced and not remarried & 241 & 6.4 \\
\hline Widowed and not remarried & 29 & 0.8 \\
\hline \multicolumn{3}{|l|}{ Rural or urban nature of residence ${ }^{\mathrm{b}}(n=3775)$} \\
\hline Urban area & 2502 & 66.3 \\
\hline Urban cluster & 973 & 25.8 \\
\hline Rural area & 300 & 7.9 \\
\hline \multicolumn{3}{|l|}{ Education level $(n=3775)$} \\
\hline Primary school & 19 & 0.5 \\
\hline Lower secondary school & 44 & 1.2 \\
\hline Upper secondary school & 391 & 10.3 \\
\hline Post-secondary/Tertiary school & 3321 & 88.0 \\
\hline \multicolumn{3}{|l|}{ Current employment status $(n=3747)$} \\
\hline Employed (Full- or Part-time) & 2547 & 68.0 \\
\hline Student & 648 & 17.3 \\
\hline Retired & 196 & 5.2 \\
\hline Unemployed & 356 & 9.5 \\
\hline Has a chronic health condition ${ }^{\mathrm{c}}(n=3774)$ & 1138 & 31.3 \\
\hline \multicolumn{3}{|l|}{ Survey language $(n=3816)$} \\
\hline English & 2525 & 66.2 \\
\hline German & 304 & 8 \\
\hline Arabic & 302 & 7.9 \\
\hline European Spanish & 262 & 6.9 \\
\hline French & 213 & 5.6 \\
\hline Italian & 98 & 2.6 \\
\hline Russian & 92 & 2.4 \\
\hline Chinese & 20 & 0.5 \\
\hline
\end{tabular}

The number of valid responses for a variable is provided in parentheses. All percentages were calculated as percent of valid responses for the variable in question

USA United States of America

${ }^{\mathrm{a} C}$ Countries accounting for $\geq 5 \%$ of respondents

${ }^{\mathrm{b}}$ Urban area: population more than 50,000 , urban cluster: population between 2500 and 50,000, rural area: population less than 2500

${ }^{c}$ Responded "yes" to the dichotomous item "Do you have any chronic mental or physical health conditions?" 
Table 2 Descriptions of the dependent, independent, mediator, and moderator variables

\begin{tabular}{|c|c|c|c|c|}
\hline & $n$ & Mean & SD & Range \\
\hline Perceived social isolation & 3814 & 2.2 & 1.7 & $0-5$ \\
\hline Depressed and anxious mood (PHQ- $4^{\mathrm{a}}$ ) & 3809 & 4.4 & 3.4 & $0-12$ \\
\hline Perceived sleep quality before the spread of SARS-CoV-2 ${ }^{\mathrm{b}}$ & 3816 & 2.0 & 0.8 & $0-3$ \\
\hline $\begin{array}{l}\text { Perceived sleep quality in the time since SARS-CoV-2 began } \\
\text { spreading }\end{array}$ & 3816 & 1.5 & 0.9 & $0-3$ \\
\hline Change in perceived sleep quality ${ }^{\mathrm{c}}$ & 3816 & -0.4 & 1.0 & -3 to +3 \\
\hline Resilience $\left(\mathrm{BRS}^{\mathrm{d}}\right)$ & 3792 & 3.4 & 0.8 & $1-5$ \\
\hline
\end{tabular}

For PHQ-4 and BRS, existing translations of validated measures were used when available

$N$ number of respondents, $S D$ standard deviation, Range observed range in the sample

${ }^{a} P H Q-4$ 4-item Patient Health Questionnaire (41)

${ }^{\mathrm{b}} \mathrm{SARS}$ - $\mathrm{CoV}-2$ severe acute respiratory syndrome coronavirus 2

${ }^{c}$ Change in perceived sleep quality perceived sleep quality since the spread of the virus minus perceived sleep quality before the spread of the virus, ${ }^{\mathrm{d}} B R S$ Brief Resilience Scale (26)
Results from the moderated mediation model are presented in Table 4. Consistent with our prediction, resilience moderated the mediating role of depressed and anxious mood in the relationship between perceived social isolation and perceived sleep quality. The indirect effect of perceived social isolation on change in perceived sleep quality through depressed and anxious mood decreased as the level of resilience increased (index of moderated mediation $=0.008, \mathrm{SE}=0.003,95 \% \mathrm{CI}[0.001 ; 0.014]$ ). As summarized in Table 4, the conditional indirect effect was significantly different from zero for all levels of resilience, and it was stronger for those with low levels of resilience compared with those with high levels of resilience $(-0.052$, bootstrapped $\mathrm{SE}=0.005$ vs -0.040 , bootstrapped $\mathrm{SE}=0.004)$.

\section{Discussion}

We found that greater perceived social isolation was associated with poorer perceived sleep quality during the COVID-19 pandemic, and this relationship was mediated by depressed and anxious mood. Furthermore, we found that resilience serves as a protective (moderating) factor in these relationships. These results extend previous research linking subjective and objective social isolation with negative mood [8-10, 43] and studies linking negative mood with sleep impairments [19, 20, 44].

Considering the positive correlation between objective and subjective social isolation [43], it is possible that the social distancing advised during the COVID-19 pandemic contributed to an increased sense of perceived isolation

Table 3 Pearson's correlations between perceived social isolation, depressed and anxious mood, perceived sleep quality, and resilience

\begin{tabular}{|c|c|c|c|c|c|c|}
\hline & (1) & (2) & (3) & (4) & (5) & (6) \\
\hline Perceived social isolation & 1 & $\begin{array}{l}0.31 * * \\
\quad(n=3807)\end{array}$ & $-0.13 * *(n=3814)$ & $-0.20 * *(=3790)$ & $-0.03(n=3814)$ & $-0.17 * *(n=3814)$ \\
\hline $\begin{array}{l}\text { Depressed and anxious mood } \\
\left(\text { PHQ-4 } 4^{\mathrm{a}}\right)\end{array}$ & & 1 & $-0.33 * *(n=3809)$ & $-0.49 * *(n=3786)$ & $0.00(n=3809)$ & $-0.37 * *(n=3809)$ \\
\hline Change in perceived sleep quality & & & 1 & $0.14 * *(n=3792)$ & $-0.51 * *(n=3816)$ & $0.67 * *(n=3816)$ \\
\hline Resilience $\left(\mathrm{BRS}^{\mathrm{c}}\right)$ & & & & 1 & $0.06 * *(n=3792)$ & $0.21 * *(n=3792)$ \\
\hline $\begin{array}{l}\text { Perceived sleep quality before the } \\
\text { spread of SARS-CoV-2 }\end{array}$ & & & & & 1 & $0.29 * *(n=3816)$ \\
\hline $\begin{array}{l}\text { Perceived sleep quality in the } \\
\text { time since SARS-CoV-2 began } \\
\text { spreading }\end{array}$ & & & & & & 1 \\
\hline
\end{tabular}

${ }^{\text {a } P H Q-4 ~ 4-i t e m ~ P a t i e n t ~ H e a l t h ~ Q u e s t i o n n a i r e ~(41) ~}$

${ }^{\mathrm{b}}$ Change in perceived sleep quality perceived sleep quality since the spread of the virus minus perceived sleep quality before the spread of the virus

${ }^{\mathrm{c}} B R S$ Brief Resilience Scale (26)

$* * \mathrm{p}<0.001$ 


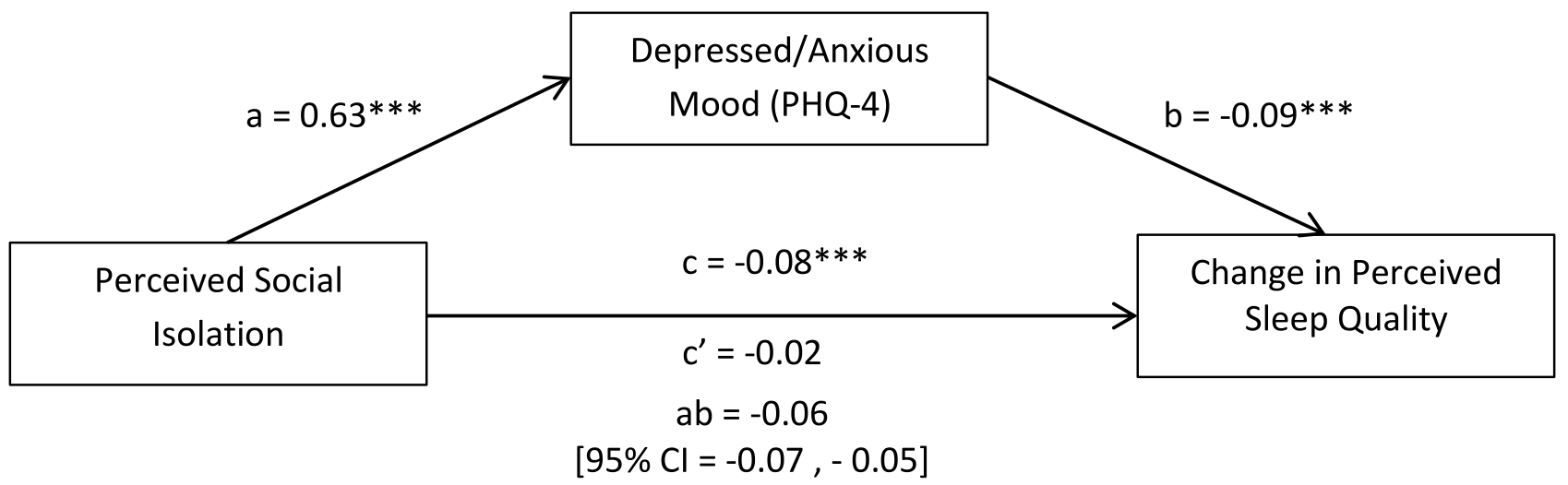

Fig. 2 Simple mediation model: Indirect effect of perceived social isolation on change in perceived sleep quality through depressed and anxious mood during the COVID-19 pandemic $(\mathrm{n}=3807)$. $P H Q$ -

[45]. These perceptions may increase depressed and anxious symptomology [46, 47] as well as cause alterations in rhythm and daily routine, both biologically and behaviorally [48, 49]. These outcomes may subsequently impact sleep quality and duration [50]. Therefore, minimizing feelings of isolation, depression, and anxiety by improving social interaction and support without jeopardizing safety may be one
4 4-item Patient Health Questionnaire (41); ${ }^{* * *} p<0.0001 ; 95 \%$ CI (confidence interval) obtained using bootstrap method

way to minimize negative effects of the pandemic. Findings from previous studies indicate that higher levels of social capital are associated with decreased anxiety and depression levels [51] and with improved physical and mental health $[27,52]$. Similar recent findings were also reported in the context of the COVID-19 pandemic [53]. Mindfulness-based interventions are another potentially promising avenue for
Table 4 Moderated mediation model results $(n=3784)$

\begin{tabular}{|c|c|c|c|c|c|c|}
\hline Effect (coefficient label) & $\beta$ & SE & $\mathrm{t}$ & $\mathrm{p}$ & 95\% LLCI & 95\% ULCI \\
\hline$X->M\left(a_{1}\right)$ & 0.72 & 0.11 & 6.24 & $<0.0001$ & 0.49 & 0.94 \\
\hline$W->M\left(a_{2}\right)$ & -1.75 & 0.10 & -17.96 & $<0.0001$ & -1.95 & -1.56 \\
\hline$X * \mathrm{~W}->M\left(a_{3}\right)$ & -0.08 & 0.03 & -2.30 & 0.02 & -0.14 & -0.01 \\
\hline$M->Y(b)$ & -0.10 & 0.005 & -18.89 & $<0.0001$ & -0.11 & -0.09 \\
\hline$X->Y\left(c^{\prime}{ }_{1}\right)$ & -0.02 & 0.04 & -0.49 & 0.62 & -0.09 & 0.05 \\
\hline$W->Y\left(c_{2}^{\prime}\right)$ & -0.04 & 0.03 & -1.30 & 0.19 & -0.11 & 0.02 \\
\hline$X^{*} W->Y\left(c_{3}^{\prime}\right)$ & 0.0005 & 0.01 & 0.04 & 0.96 & -0.02 & 0.02 \\
\hline \multicolumn{7}{|l|}{ Conditional direct effect ${ }^{\mathrm{a}}$} \\
\hline Low level of resilience & -0.017 & 0.01 & -1.37 & 0.17 & -0.042 & 0.007 \\
\hline Mean level of resilience & -0.017 & 0.01 & -1.76 & 0.08 & -0.036 & 0.002 \\
\hline \multirow[t]{2}{*}{ High level of resilience } & -0.016 & 0.01 & -1.23 & 0.22 & -0.043 & 0.010 \\
\hline & $\beta$ & Boot SE & & & Boot $95 \%$ LLCI & Boot $95 \%$ ULCI \\
\hline \multicolumn{7}{|l|}{ Conditional indirect effect ${ }^{\mathrm{a}}$} \\
\hline Low level of resilience & -0.052 & 0.005 & & & -0.062 & -0.042 \\
\hline Mean level of resilience & -0.046 & 0.004 & & & -0.054 & -0.038 \\
\hline High level of resilience & -0.040 & 0.004 & & & -0.048 & -0.031 \\
\hline Index of moderated mediation & 0.008 & 0.003 & & & 0.001 & 0.014 \\
\hline
\end{tabular}

When relevant, the labels used to identify model coefficients in the statistical diagram depicted in Fig. 1b are included within parentheses in column 1

$X$ perceived social isolation, $M$ depressed and anxious mood, $W$ resilience, $Y$ change in perceived sleep quality, $S E$ standard error, $t$ Student's $t$ value, $p$ Student's test $p$ value, $L L C I$ lower limit confidence interval, ULCI upper limit confidence interval, Boot bootstrap

${ }^{a}$ Effects were probed at the mean (3.4, mean), at one standard deviation above the mean (4.2, high level), and at one standard deviation below the mean (2.6, low level) of the moderator (resilience) 
consideration, as studies have found that mindfulness interventions can reduce feelings of depression and anxiety [54, 55].

Our finding that resilience serves as a moderator highlights another promising area for targeted interventions. In fact, the results suggest that individuals who are low in resilience may be especially at-risk for depressed and anxious mood as well as sleep impairments. The protective role of resilience against negative affect has been addressed in many studies [56-58], and resilience interventions have shown their effectiveness in reducing stress, depression, and anxiety $[59,60]$. Given our finding that negative moods predict poorer sleep quality, combined with research documenting a relationship between sleep quality and immune functioning [61], protecting individuals from elevated negative moods may be particularly important during a pandemic. In the context of COVID-19, healthy immune functioning is important for staving-off negative health consequences of the virus, and interventions focusing on boosting resilience may indirectly enhance individuals' psychological (mood) and physical (immune system) health both during the pandemic as well as in the face of other stressful life events.

Though the results of this study are meaningful and novel, we should point-out some limitations. First, the convenience sample may limit generalizability of the study results. Second, the cross-sectional design of this study cannot rule-out alternative causal directions in the relationships among variables in our models. Although there is potential for levels of perceived isolation, negative mood, and/ or perceived sleep quality to change over-time and across countries as the spread of COVID-19 and mitigation policies evolve, we expect that the theoretical relationships that we predicted and observed would hold across time and place. Third, perceived sleep quality was reported retrospectively, and current mood or "rosy retrospection" [62] may have biased perceptions of former (pre-COVID-19) sleep quality. In addition, the self-reported nature of our sleep quality assessment limits our findings to subjective sleep quality. Finally, although the items were face-valid, this study used unvalidated single-item measures to assess perceived sleep quality and perceived social isolation; therefore, results should be interpreted with caution. Future replication studies with multi-item validated measures and cohort studies with more objective assessments should be performed to deepen our understanding of how sleep may be influenced by perceived isolation and negative moods. Despite these limitations, this study was among the first to be launched to capture the nature of individuals' experiences during the COVID-19 pandemic; therefore, it provides time-sensitive observations during the pandemic's global escalation. Furthermore, the experiences (perceived isolation, negative mood, poor sleep quality) and protective factors (resilience) examined in this study are relevant and extend well beyond the context of the COVID-19 pandemic.

In conclusion, the current study is among the first to examine the role of resilience in moderating the relationships among feelings of isolation, depressed and anxious mood, and perceived sleep quality. We found that greater perceived social isolation was associated with elevated depressed and anxious mood and with lower perceived sleep quality. Moreover, we found that individuals with higher levels of psychological resilience are less at-risk of experiencing these negative outcomes. These findings suggest that interventions focusing on improving and promoting resilience and social support may help to reduce deleterious mental and physical health consequences of feeling socially isolated.

Acknowledgments We would like to acknowledge the help of the Stress and Resilience in the Face of Coronavirus (COVID-19) Survey team members and collaborators (Hailey Glewwe, Ryan Johnson, Luke Leufen, Ksenia F. Li, Huma Mamtiminm, Daniela Morales, Katania Myrie, Jake Robinson, Stephan Bongard, Bingshuo Li, Shah Alem, Svetlana Kuzmina, Susan Levenstein, Motohiro Nakajima, Marina Olmos, Georgi Vasilev, R. J. Solomon, Emna Bouguira, Emanuele Capuozzo).

Funding Part of Dr. al'Absi time was supported by grants from the National Institute of Health (R01DA016351 and R01DA027232).

\section{Compliance with Ethical Standard}

Conflict of Interest The authors declare that they have no conflict of interest.

Informed Consent Informed consent was obtained from all individual participants included in the study.

Ethical Approval All procedures performed in studies involving human participants were in accordance with the ethical standards of the institutional and/or national research committee and with the 1964 Helsinki declaration and its later amendments or comparable ethical standards.

\section{References}

1. WHO Director-General's opening remarks at the media briefing on COVID-19 - 11 March 2020 [press release]. 2020.

2. World Health Organization. International Health Regulations (IHR) on procedures concerning Public Health Emergencies of International Concern (PHEIC). 2005.

3. World Health Organization. Coronavirus disease (COVID-19). Situation Report - 174. 2020.

4. Alradhawi M, Shubber N, Sheppard J, Ali Y. Effects of the COVID-19 pandemic on mental well-being amongst individuals in society-a letter to the editor on "The socio-economic implications of the coronavirus and COVID-19 pandemic: a review." Int J Surg. 2020;78:147-8.

5. Vindegaard N, Benros ME. COVID-19 pandemic and mental health consequences: systematic review of the current evidence. Brain Behav Immun. 2020. 
6. Hale T, Noam Angrist E, Cameron-Blake L, Hallas B, Kira S, Majumdar A, et al. Oxford COVID-19 government response tracker: Blavatnik School of Government; 2020 [Available from: https://www.bsg.ox.ac.uk/research/research-projects/coronavirusgovernment-response-tracker.

7. Ozamiz-Etxebarria N, Dosil-Santamaria M, Picaza-Gorrochategui M, Idoiaga-Mondragon N. Stress, anxiety, and depression levels in the initial stage of the COVID-19 outbreak in a population sample in the northern Spain. Cad Saude Publica. 2020;36(4):e00054020.

8. Leigh-Hunt N, Bagguley D, Bash K, Turner V, Turnbull S, Valtorta $\mathrm{N}$, et al. An overview of systematic reviews on the public health consequences of social isolation and loneliness. Public Health. 2017;152:157-71.

9. Matthews T, Danese A, Wertz J, Odgers CL, Ambler A, Moffitt TE, et al. Social isolation, loneliness and depression in young adulthood: a behavioural genetic analysis. Soc Psychiatry Psychiatr Epidemiol. 2016;51(3):339-48.

10. Domènech-Abella J, Mundó J, Haro JM, Rubio-Valera M. Anxiety, depression, loneliness and social network in the elderly: Longitudinal associations from The Irish Longitudinal Study on Ageing (TILDA). J Affect Disord. 2019;246:82-8.

11. Wu KK, Chan SK, Ma TM. Posttraumatic stress, anxiety, and depression in survivors of severe acute respiratory syndrome (SARS). J Trauma Stress. 2005;18(1):39-42.

12. Moldofsky H, Patcai J. Chronic widespread musculoskeletal pain, fatigue, depression and disordered sleep in chronic post-SARS syndrome; a case-controlled study. BMC Neurol. 2011;11:37.

13. Lee AM, Wong JG, McAlonan GM, Cheung V, Cheung C, Sham PC, et al. Stress and psychological distress among SARS survivors 1 year after the outbreak. Can J Psychiatry. 2007;52(4):233-40.

14. Liu X, Kakade M, Fuller CJ, Fan B, Fang Y, Kong J, et al. Depression after exposure to stressful events: lessons learned from the severe acute respiratory syndrome epidemic. Compr Psychiatry. 2012;53(1):15-23.

15. Wang C, Pan R, Wan X, Tan Y, Xu L, Ho CS, et al. Immediate psychological responses and associated factors during the initial stage of the 2019 coronavirus disease (COVID-19) epidemic among the general population in China. Int J Environ Res Public Health. 2020;17(5).

16. Czeisler M, Lane RI, Petrosky E, Wiley JF, Christensen A, Njai $\mathrm{R}$, et al. Mental health, substance use, and suicidal ideation during the COVID-19 pandemic-United States, June 24-30, 2020. MMWR Morb Mortal Wkly Rep. 2020;69(32):1049-57.

17. Daly M, Sutin AR, Robinson E. Depression reported by US adults in 2017-2018 and March and April 2020. J Affect Disord. 2020;278:131-5.

18. Ettman CK, Abdalla SM, Cohen GH, Sampson L, Vivier PM, Galea S. Prevalence of depression symptoms in US adults before and during the COVID-19 pandemic. JAMA Netw Open. 2020;3(9):e2019686.

19. Shen L, van Schie J, Ditchburn G, Brook L, Bei B. Positive and negative emotions: differential associations with sleep duration and quality in adolescents. J Youth Adolesc. 2018;47(12):2584-95.

20. Wang S, Xie L, Xu Y, Yu S, Yao B, Xiang D. Sleep disturbances among medical workers during the outbreak of COVID-2019. Occup Med (Lond). 2020.

21. Irwin M. Effects of sleep and sleep loss on immunity and cytokines. Brain Behav Immun. 2002;16(5):503-12.

22. Cohen S, Doyle WJ, Alper CM, Janicki-Deverts D, Turner RB. Sleep habits and susceptibility to the common cold. Arch Intern Med. 2009;169(1):62-7.

23. van Leeuwen WM, Lehto M, Karisola P, Lindholm H, Luukkonen R, Sallinen M, et al. Sleep restriction increases the risk of developing cardiovascular diseases by augmenting proinflammatory responses through IL-17 and CRP. PLoS ONE. 2009;4(2): 4589 .

24. Besedovsky L, Lange T, Haack M. The sleep-immune crosstalk in health and disease. Physiol Rev. 2019;99(3):1325-80.

25. Lange T, Perras B, Fehm HL, Born J. Sleep enhances the human antibody response to hepatitis A vaccination. Psychosom Med. 2003;65(5):831-5.

26. Smith BW, Dalen J, Wiggins K, Tooley E, Christopher P, Bernard $\mathrm{J}$. The brief resilience scale: assessing the ability to bounce back. Int J Behav Med. 2008;15(3):194-200.

27. Li C, Jiang S, Fang X. Effects of multi-dimensional social capital on mental health of children in poverty: an empirical study in Mainland China. J Health Psychol. 2020;25(6):853-67.

28. Rodríguez-Rey R, Alonso-Tapia J, Hernansaiz-Garrido H. Reliability and validity of the Brief Resilience Scale (BRS) Spanish Version. Psychol Assess. 2016;28(5):e101-10.

29. Chmitorz A, Wenzel M, Stieglitz RD, Kunzler A, Bagusat C, Helmreich I, et al. Population-based validation of a German version of the Brief Resilience Scale. PLoS ONE. 2018;13(2):e0192761.

30. Lai JCL, Yue X. Using the Brief Resilience Scale to assess Chinese people's ability to bounce back from stress. SAGE Open. October 2014.

31. Jacobs I, Horsch A. Psychometric properties of the French Brief Resilience Scale. Eur J Health Psychol. 2019;26(1):1-9.

32. Kliem S, Mößle T, Klatt T, Fleischer S, Kudlacek D, Kröger $\mathrm{C}$, et al. Psychometric evaluation of an Arabic version of the PHQ-4 based on a representative survey of Syrian refugees. Psychother Psychosom Med Psychol. 2016;66(9-10):385-92.

33. Löwe B, Wahl I, Rose M, Spitzer C, Glaesmer H, Wingenfeld $\mathrm{K}$, et al. A 4-item measure of depression and anxiety: validation and standardization of the Patient Health Questionnaire-4 (PHQ-4) in the general population. J Affect Disord. 2010;122(1-2):86-95.

34. Diez-Quevedo C, Rangil T, Sanchez-Planell L, Kroenke K, Spitzer RL. Validation and utility of the patient health questionnaire in diagnosing mental disorders in 1003 general hospital Spanish inpatients. Psychosom Med. 2001;63(4):679-86.

35. Baca E, Saiz J, Agüera L, Caballero L, Fernández Liria A, Ramos J, et al. Validación de la versión española del PRIME-MD: un procedimiento para el diagnóstico de trastornos mentales en atención primaria. Actas Españolas de Psiquiatría. 1999;27(6):375-83.

36. Carballeira Y, Dumont P, Borgacci S, Rentsch D, de Tonnac N, Archinard M, et al. Criterion validity of the French version of Patient Health Questionnaire (PHQ) in a hospital department of internal medicine. Psychol Psychother. 2007;80(Pt 1):69-77.

37. Yeung A, Fung F, Yu SC, Vorono S, Ly M, Wu S, et al. Validation of the Patient Health Questionnaire-9 for depression screening among Chinese Americans. Compr Psychiatry. 2008;49(2):211-7.

38. Pogosova N-GV, Dovzhenko TV, Babin AG, Kursakov A, Vygodin VA. Russian version of PHQ-2 and 9 questionnaires: sensitivity and specificity in detection of depression in outpatient general medical practice. Cardiovascular Therapy and Prevention (Russian Federation). 13(3):18-24.

39. García-Campayo J, Zamorano E, Ruiz MA, Pérez-Páramo M, López-Gómez V, Rejas J. The assessment of generalized anxiety disorder: psychometric validation of the Spanish version of the self-administered GAD-2 scale in daily medical practice. Health Qual Life Outcomes. 2012;10:114.

40. Micoulaud-Franchi JA, Lagarde S, Barkate G, Dufournet B, Besancon C, Trébuchon-Da Fonseca A, et al. Rapid detection of generalized anxiety disorder and major depression in epilepsy: validation of the GAD-7 as a complementary tool to the NDDI-E in a French sample. Epilepsy Behav. 2016;57(Pt A):211-6. 
41. Kroenke K, Spitzer RL, Williams JB, Löwe B. An ultra-brief screening scale for anxiety and depression: the PHQ-4. Psychosomatics. 2009;50(6):613-21.

42. Hayes AF. Introduction to mediation, moderation, and conditional process analysis : a regression-based approach. Second edition. ed2018.

43. Cho JH, Olmstead R, Choi H, Carrillo C, Seeman TE, Irwin MR. Associations of objective versus subjective social isolation with sleep disturbance, depression, and fatigue in community-dwelling older adults. Aging Ment Health. 2019;23(9):1130-8.

44. Harris RA, Qualter P, Robinson SJ. Loneliness trajectories from middle childhood to pre-adolescence: impact on perceived health and sleep disturbance. J Adolesc. 2013;36(6):1295-304.

45. Tull MT, Edmonds KA, Scamaldo KM, Richmond JR, Rose JP, Gratz KL. Psychological outcomes associated with stay-at-home orders and the perceived impact of COVID-19 on daily life. Psychiatry Res. 2020;289:113098.

46. Erzen E, Çikrikci Ö. The effect of loneliness on depression: a meta-analysis. Int J Soc Psychiatry. 2018;64(5):427-35.

47. Sher L. The impact of the COVID-19 pandemic on suicide rates. QJM. 2020.

48. Helfrich-Förster C. Interactions between psychosocial stress and the circadian endogenous clock. Psych J. 2017;6(4):277-89.

49. Koch CE, Leinweber B, Drengberg BC, Blaum C, Oster H. Interaction between circadian rhythms and stress. Neurobiol Stress. 2017;6:57-67.

50. Kim EJ, Dimsdale JE. The effect of psychosocial stress on sleep: a review of polysomnographic evidence. Behav Sleep Med. 2007;5(4):256-78.

51. Valencia-Garcia D, Simoni JM, Alegría M, Takeuchi DT. Social capital, acculturation, mental health, and perceived access to services among Mexican American women. J Consult Clin Psychol. 2012;80(2):177-85.

52. Yamada Y, Suematsu M, Takahashi N, Okazaki K, Yasui H, Hida $\mathrm{T}$, et al. Identifying the social capital influencing diabetes control in Japan. Nagoya J Med Sci. 2018;80(1):99-107.

53. Xiao H, Zhang Y, Kong D, Li S, Yang N. Social capital and sleep quality in individuals who self-isolated for 14 days during the coronavirus disease 2019 (COVID-19) outbreak in January 2020 in China. Med Sci Monit. 2020;26:e923921.
54. Cavanagh K, Strauss C, Cicconi F, Griffiths N, Wyper A, Jones F. A randomised controlled trial of a brief online mindfulness-based intervention. Behav Res Ther. 2013;51(9):573-8.

55. Cavanagh K, Churchard A, O'Hanlon P, Mundy T, Votolato P, Jones $\mathrm{F}$, et al. A randomised controlled trial of a brief online mindfulness-based intervention in a non-clinical population: replication and extension. Mindfulness (N Y). 2018;9(4):1191-205.

56. Kim J, Seok JH, Choi K, Jon DI, Hong HJ, Hong N, et al. The protective role of resilience in attenuating emotional distress and aggression associated with early-life stress in young enlisted military service candidates. J Korean Med Sci. 2015;30(11):1667-74.

57. Nakazawa K, Noda T, Ichikura K, Okamoto T, Takahashi Y, Yamamura T, et al. Resilience and depression/anxiety symptoms in multiple sclerosis and neuromyelitis optica spectrum disorder. Mult Scler Relat Disord. 2018;25:309-15.

58. Shin YC, Kim SM, Kim H, Min KJ, Yoo SK, Kim EJ, et al. Resilience as a protective factor for depressive mood and anxiety among korean employees. J Korean Med Sci. 2019;34(27):e188.

59. Stonnington CM, Darby B, Santucci A, Mulligan P, Pathuis P, Cuc A, et al. A resilience intervention involving mindfulness training for transplant patients and their caregivers. Clin Transplant. 2016;30(11):1466-72.

60. Smith JL, Hanni AA. Effects of a savoring intervention on resilience and well-being of older adults. J Appl Gerontol. 2019;38(1):137-52.

61. Prather AA, Marsland AL, Hall M, Neumann SA, Muldoon MF, Manuck SB. Normative variation in self-reported sleep quality and sleep debt is associated with stimulated pro-inflammatory cytokine production. Biol Psychol. 2009;82(1):12-7.

62. Mitchell T, Thompson L. A theory of temporal adjustments of the evaluation of events: Rosy Prospection \& Rosy Retrospection. In: Stubbart C, Porac J, Meindl J, editors. Advances in managerial cognition and organizational information-processing 1994. $\mathrm{p}$. 85-114.

Publisher's Note Springer Nature remains neutral with regard to jurisdictional claims in published maps and institutional affiliations. 